\title{
Structural materialization of stainless steel molds and dies by the low temperature high density plasma nitriding
}

\author{
Tatsuhiko Aizawa ${ }^{1, a}$, Tatsuya Fukuda ${ }^{2}$, and Hiroshi Morita ${ }^{3}$ \\ ${ }^{1}$ Department of Engineering and Design, Shibaura Institute of Technology, Tokyo 108-8548, Japan \\ ${ }^{2}$ Research Center, Kimura Precision, Co. Ltd., Kyoto 615-8245, Japan \\ ${ }^{3}$ Nano-Coat Laboratory, LLC., Tokyo 144-0045, Japan
}

\begin{abstract}
Various kinds of stainless steels have been widely utilized as a mold substrate material for injection molding and as a die for mold-stamping and direct stamping processes. Since they suffered from high temperature transients and thermal cycles in practice, they must be surface-treated by dry and wet coatings, or, by plasma nitriding. Martensitic stainless steel mold was first wet plated by the nickel phosphate (NiP), which was unstable at the high temperature stamping condition; and, was easy to crystalize or to fracture by itself. This issue of nuisance significantly lowered the productivity in fabrication of optical elements at present. In the present paper, the stainless steel mold was surface-treated by the low-temperature plasma nitriding. The nitrided layer by this surface modification had higher nitrogen solute content than 4 mass\%; the maximum solidsolubility of nitrogen is usually 0.1 mass $\%$ in the equilibrium phase diagram. Owing to this solid-solution with high nitrogen concentration, the nitrided layer had high hardness of $1400 \mathrm{Hv}$ within its thickness of $40 \mu \mathrm{m}$ without any formation of nitrides after $14.4 \mathrm{ks}$ plasma nitriding at $693 \mathrm{~K}$. This nitrogen solid-solution treated stainless steel had thermal resistivity even at the mold-stamping conditions up to $900 \mathrm{~K}$.
\end{abstract}

\section{Introduction}

Various kinds of stainless steels have been widely utilized as mold substrate materials for injection molding of plastics and as a mold-die for mold-stamping and direct stamping of oxide glasses. For examples, AISI420 martensitic stainless steels, graded by STAVAX in commercial, is used as a mold for plastic injection molding. AISI316L austenitic stainless steels are also employed as a mold-die for mold-stamping of oxide glasses. In the former, heat treatment or case-hardening processes can afford to provide the sufficient hardness to molds, working around 500 to $600 \mathrm{~K}$. In the latter, since the glasstransition temperature $\left(\mathrm{T}_{\mathrm{g}}\right)$ of oxide glasses is much higher than plastics, most of molds must be coated or plasma nitrided to build up the hardened layer with heat resistance and endurance against galling [1]. In commercial, stainless steel mold is first wet plated by the nickel phosphate (NiP). Then, fine micro-textures are machined into this amorphous NiP layer; this original micro-patterns are duplicated

\footnotetext{
${ }^{a}$ Corresponding author: taizawa@sic.shibaura-it.ac.jp
}

This is an Open Access article distributed under the terms of the Creative Commons Attribution License 4.0, which permits unrestricted use, distribution, and reproduction in any medium, provided the original work is properly cited. 


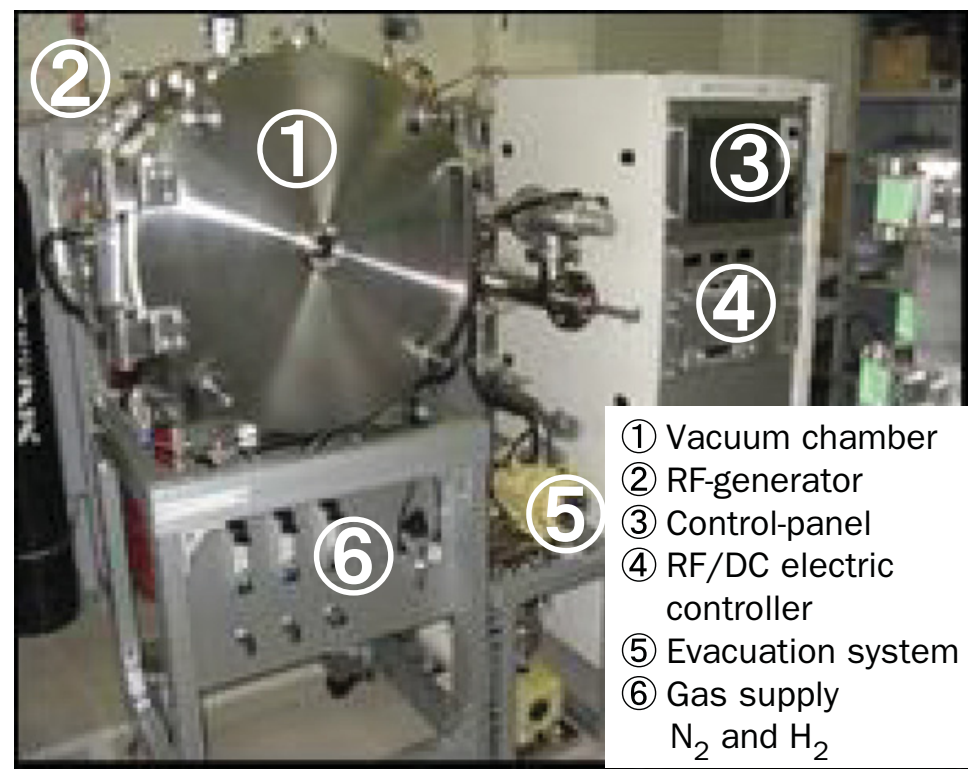

Figure 1. RF-DC plasma nitriding system, working even in the low temperature.

onto the oxide glasses by mold-stamping as an optical element. However, this NiP is unstable at the high temperature stamping condition; it is easy to crystalize or to fracture by itself. This issue of nuisance significantly lowers the productivity in fabrication of optical elements at present [2]. The authors [3-5] have developed the high density plasma nitriding process for $\mathrm{Fe}-\mathrm{Cr}$ binary alloys and stainless steels. In particular, low temperature RF-DC plasma nitriding is effective to solid solution hardening of martensitic and austenitic stainless steels [6].

In the present paper, the stainless steel mold is surface-treated by the low-temperature plasma nitriding. The nitrided layer by this surface modification has higher nitrogen solute content than 4 mass $\%$; the maximum solid-solubility of nitrogen is usually 0.1 mass $\%$ in the equilibrium phase diagram. Owing to this solid-solution with high nitrogen concentration, the nitrided layer has high hardness up to $1400 \mathrm{Hv}$ within its thickness of $40 \mu \mathrm{m}$ without any formation of nitrides after $14.4 \mathrm{ks}$ plasma nitriding at $693 \mathrm{~K}$. Different from NiP, this nitrogen solid-solution treated stainless steel has thermal resistivity even at the mold-stamping conditions up to $900 \mathrm{~K}$. Two colored oxide glass plates are deformed and joined with success into one optical element by mold-stamping with use of the low temperature nitrided stainless steel molds.

\section{Experimental procedure}

The developed RF-DC plasma nitriding system is explained together with the table-top CNC moldstamping system.

\subsection{Plasma nitriding system}

High density nitriding system has no mechanical matching box with slow response time of $1 \mathrm{~s}$ to $10 \mathrm{~s}$ to adjust the applied power. Since input and out powers are automatically matched by frequency adjustment around $2 \mathrm{MHz}$, the matching response time is only limited to $1 \mathrm{~ms}$ at most. This prompt power control provides to make full use of meso-plasma pressure range over $50 \mathrm{~Pa}$. Figure 1 illustrates the present 

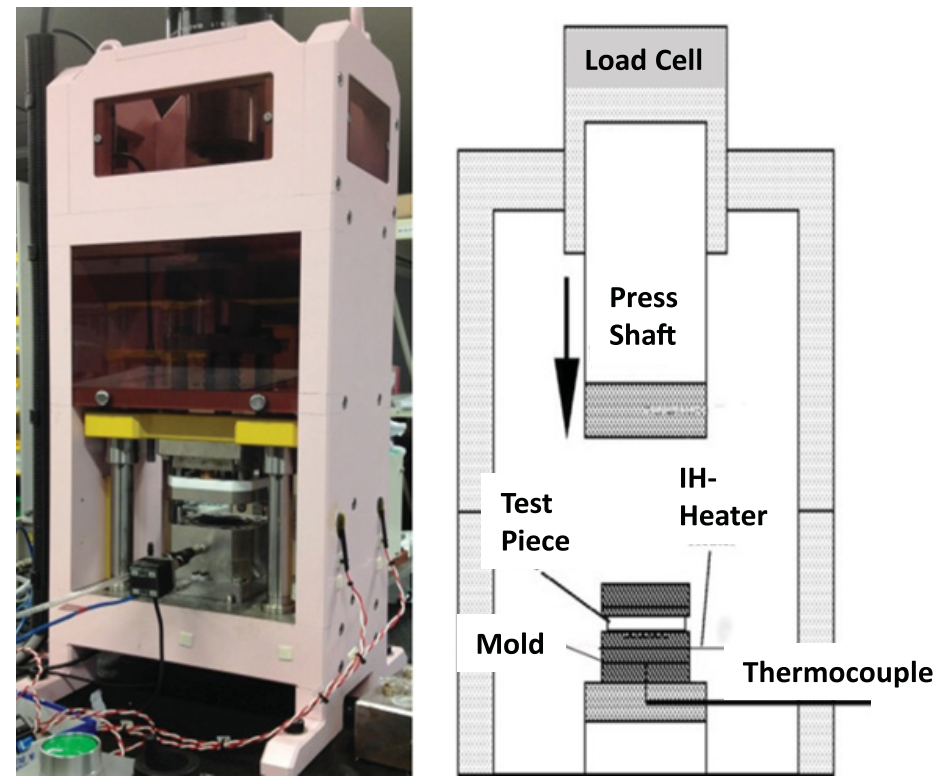

Figure 2. A mold stamping system for net-shaping and joining of oxide glasses.

system. Different from the conventional processes, the vacuum chamber is electrically neutral so that RF-power and DC-bias should be controlled independently from each other. A dipole electrode is utilized to generate RF-plasma; DC bias is directly applied to the specimens. Heating unit is located under this DC-biased cathode plate.

In the following nitriding experiments, the specimens are located on the cathode table before evacuation down to the base pressure of $0.1 \mathrm{~Pa}$. Then, nitrogen gas is first introduced as a carrier gas for heating. After heating to the specified holding temperature, nitrogen pre-sputtering is started at the constant pressure, $70 \mathrm{~Pa}$ only by the DC-bias of $-500 \mathrm{~V}$. After pre-sputtering for $1.8 \mathrm{ks}$, the hydrogen gas was added to nitrogen gas with the specified partial pressure ratio; i.e. the flow rate of $\mathrm{N}_{2}$ gas is $100 \mathrm{ml} / \mathrm{min}$, and, $\mathrm{H}_{2}, 20 \mathrm{ml} / \mathrm{min}$. RF-voltage, DC-bias and the pressure are constant by $250 \mathrm{~V},-300 \mathrm{~V}$ and $70 \mathrm{~Pa}$, respectively. After nitriding at $693 \mathrm{~K}$ for $14.4 \mathrm{ks}$, the chamber is bent down to the atmospheric pressure by nitrogen gas to pick up the nitride specimens and molds.

\subsection{Specimen and mold}

Martensitic stainless steel AISI420 specimens and molds were prepared to have either surface polished. The specimen was shaped by $25 \times 25 \times 5 \mathrm{~mm}^{3}$; the mold, the circular disc with the diameter of $25 \mathrm{~mm}$ and the thickness of $5 \mathrm{~mm}$.

\subsection{Mold-stamping system}

Mold-stamping test was performed by the CNC table-top stamping system, as shown in Fig. 2. Both the applied load and stroke are numerically controlled up to $50 \mathrm{kN}$ and $100 \mathrm{~mm}$, respectively. Since each step in the stamping advances by $0.1 \mu \mathrm{m}$, fine micro-patterns are imprinted onto the work materials by using a precise mother tool [7]. Different from the electrically resistant heating unit, ultrahigh frequency induction heating (UHFIH) device is utilized to make rapid heating and quenching. This device works around $2 \mathrm{MHz}$; only the upper and lower molds with the work materials are directly heated to sustain the holding temperature during micro-forming of work materials. Furthermore, the sequential control 

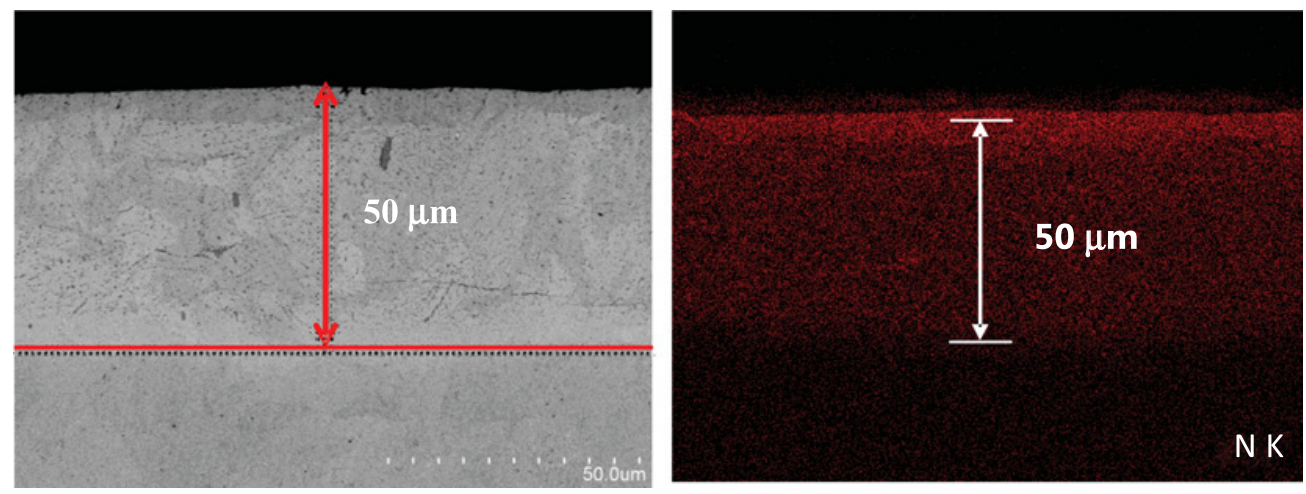

Figure 3. SEM image and nitrogen mapping on the cross-section of nitrided layer.

of input power in this device enables us to suppress the temperature deviation with the tolerance of $1 \mathrm{~K}$ and to make rapid cooling. This accurate thermal control results in high qualification in mold-stamping just above the glass transition temperature. To be free from severe oxidation, the vacuum cassette mold system is constructed so that the mold-stamping should take place under $100 \mathrm{~Pa}$.

\section{Experimental results and discussion}

AISI420 specimens and molds are utilized to investigate the microstructural analysis and hardness testing of nitrided layers and the hot deformation of oxide glasses at $833 \mathrm{~K}$, respectively.

\subsection{Low temperature plasma nitriding}

The nitrided AISI420 specimen at $693 \mathrm{~K}$ for $14.4 \mathrm{ks}$ was halved by wire-cutting to investigate the microstructure and nitrogen solute map on its cross-section. SEM and EDX were utilized to describe the nitrogen concentration in the depth of nitrided layer. Figure 3 depicts the SEM and nitrogen mapping in the cross-section of nitrided martensitic stainless steel specimen.

Only after nitriding for $14.4 \mathrm{ks}$, the nitrided thickness reaches to $50 \mu \mathrm{m}$. At the vicinity of surface, the nitrogen solute content becomes 9 mass $\%$ in average. The nitrogen content decreases from this high concentration to 4 mass $\%$ in the middle range of thickness and goes to nearly zero near the nitriding front end. On the other hand, no change is detected in the chromium concentration along the depth of nitrided layer. This also proves that no $\mathrm{CrN}$ should be synthesized as the precipitate in the nitrided layer from the surface of specimen. No precipitation reaction to $\mathrm{CrN}$ is intrinsic to this low temperature plasma nitriding; in [8], formation of fine $\mathrm{CrN}$ precipitates with higher volume fraction is needed to make hardening in the normal plasma nitriding under higher temperature than $723 \mathrm{~K}$. High nitrogen solute content also characterizes the inner nitriding behaviour of stainless steels. In the equilibrium phase diagram, the maximum solid solubility of nitrogen in a-Fe matrix is limited to 0.1 mass $\%$ at $773 \mathrm{~K}$. Since the detected $\alpha$-Fe peak of nitrided specimen shifts to the lower $2 \theta$ side, the $\alpha$-Fe lattice structure expands itself by site occupation of nitrogen solute into vacancy sites. This nitrogen solid solution with high concentration drives the hardening process.

The above nitrogen mapping information reveals that $\mathrm{N} /(\mathrm{N}+\mathrm{Fe})$ ratio is 27 to 28 at $\%$, corresponding to 9 mass $\%$, at the vicinity of surface and that $\mathrm{N} /(\mathrm{N}+\mathrm{Fe})$ ratio is 15 to 17 at $\%$, corresponding to 4 mass $\%$, in the middle of the nitrided layer except for the vicinity of nitriding front end. Assuming that the occupation process of nitrogen interstitials into octahedral and tetrahedral vacancies, or, $\mathrm{V}_{\text {oct }}$ and $\mathrm{V}_{\text {tra }}$ advances from the surface, two pairs of $\mathrm{V}_{\text {oct }}$ and $\mathrm{V}_{\text {tra }}$ are occupied by nitrogen solutes at the vicinity 


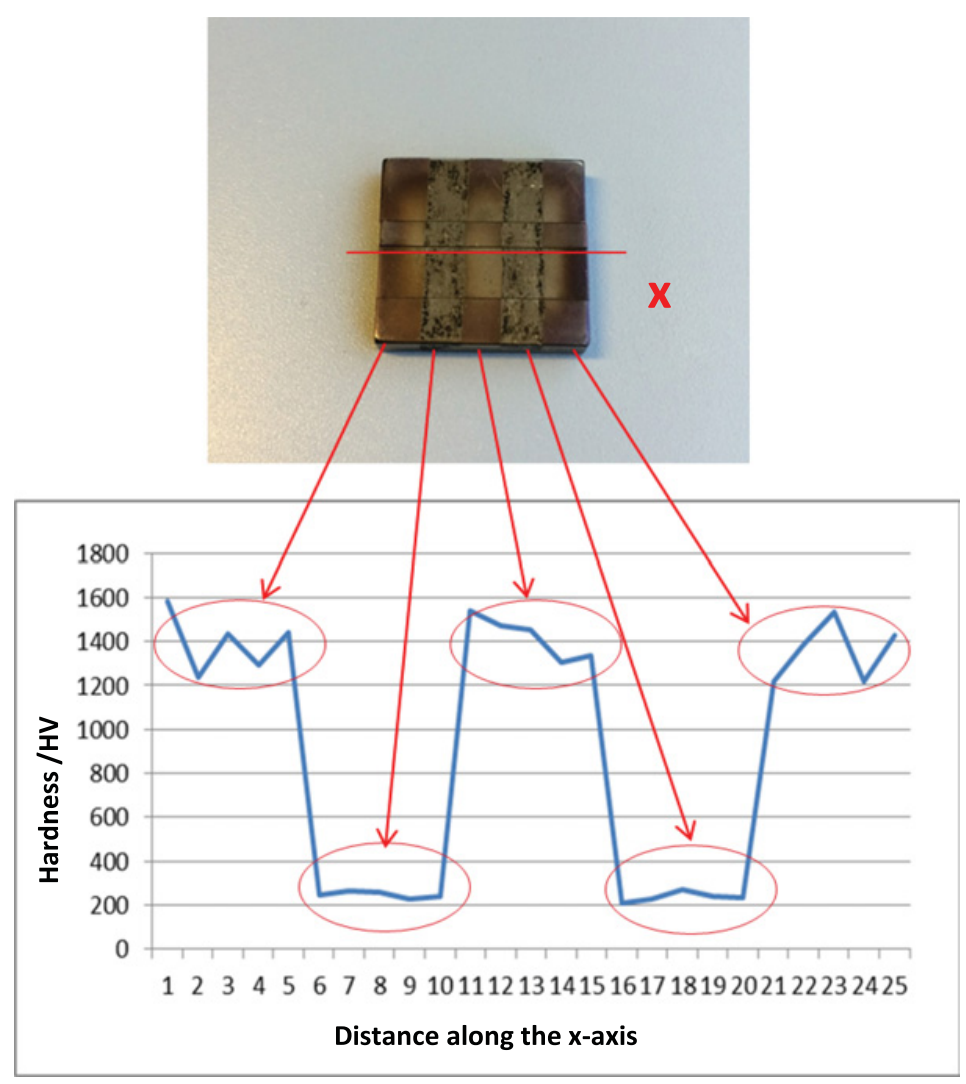

Figure 4. Surface hardness distribution across two stripe masks on the AISI420 specimen.

of surface, and, one pair of $\mathrm{V}_{\text {oct }}$ and $\mathrm{V}_{\text {tra }}$, in the middle of the nitrided layer. In the former, since the $\alpha$-Fe supercell is much distorted by occupation of nitrogen into two pair of vacancies, the original $\alpha$-Fe transforms to more relaxed crystalline structure or $\gamma$-Fe. On the other hand, the nitrogen solute content decreases with further nitrogen atom diffusion into the depth in the middle range of the nitrided layer; only one pair of vacancies is occupied by nitrogen. Under this occupation process, the $\alpha$-Fe supercell is less strained and never accompanied with the above phase transformation.

ASIS420 specimen with two stripe masks on its surface was prepared and nitrided at $693 \mathrm{~K}$ for $7.2 \mathrm{ks}$ to investigate the hardness distribution across these two stripe masks along the center-line on the specimen surface as shown in Fig. 4.

Since the masked regions are free from nitriding and remain as they were before nitriding, the measured hardness is equivalent to the AISI420 matrix hardness of $250 \mathrm{Hv}$. On the other hand, the unmasked or nitrided regions have much higher hardness than $1400 \mathrm{Hv}$ even after plasma nitriding for $7.2 \mathrm{ks}$. This high hardness is caused by the solid solution strengthening via high nitrogen solute concentration in the $\alpha$-Fe lattices of AISI420 stainless steels.

\subsection{Hot Molding stamping test}

The nitrided layer of AISI420 by the present low temperature plasma nitriding has characteristic microstructure, where the original $\alpha$-Fe supercell has four nitrogen solute atoms locating at two pairs of tetrahedral and octahedral vacancy sites near the surface and two nitrogen solute atoms locating at a 


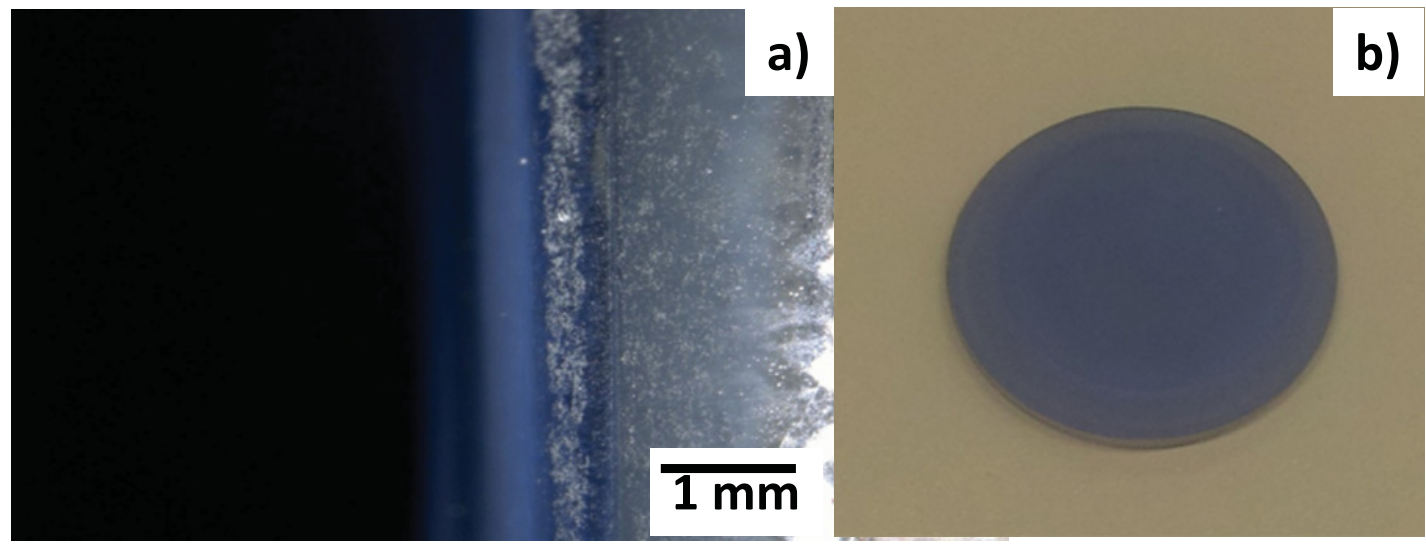

Figure 5. Hot mold stamping to join two colored oxide glass plates to one optical element at $833 \mathrm{~K}$.

single pair in depth. Hence, the oxygen atoms are expected not to penetrate into the nitrided layer and not to form oxides at the vicinity of surface when mold-stamping even in air.

In this experiment, two colored oxide glass plates with different $T_{\mathrm{g}}$ and thickness were mold-stamped at $833 \mathrm{~K}$ for $3.6 \mathrm{ks}$ under the programmed thermal cycling schedule to be free from fracture. Figure 5a) depicted the cross-section of two oxide glass plates and nitrided mold. Under the reduction of thickness by $8 \%$, two oxide glasses were uniformly compressed and joined together with each other. Figure $5 \mathrm{~b}$ ) shows the jointed glass plate after successful demolding from the nitrided mold.

\section{Conclusion}

The solid-solution hardened stainless steels by low temperature plasma nitriding work as a heat resistant mold for hot stamping and injection molding of oxide glasses and high- $\mathrm{T}_{\mathrm{g}}$ plastics. Its features with the nitrided layer thickness over $40 \mu \mathrm{m}$ and the surface hardness over $1400 \mathrm{Hv}$ by nitriding at $693 \mathrm{~K}$ for $14.4 \mathrm{ks}$ or four hours, are attractive for production of optical elements with being free from hot galling and severe abrasive wear. In particular, the average nitrogen solute content of 4 mass $\%$ or 15 at $\%$ is useful to prevent the hot-stamping mold from galling with oxide glasses in hot, vacuum condition. Further studies are planned to utilize this nitrided AISI420 material for shaping and machining to have well-defined geometry to optical element and to use it as a mold to duplicate its geometry into the high- $\mathrm{T}_{\mathrm{g}}$ oxide glasses in accurate.

The authors would like to express their gratitude to Mr. S. Kurozumi and Mr. H. Yamagata for their help in mold stamping experiments of oxide glasses. This study is financially supported by MEXT with the contract of \# 411419.

\section{References}

[1] T. Aizawa, F-J. Hoe, S. Yukawa, Res. Rep. SIT 55-1 (2011) 34-43

[2] MITI, Supporting industry report on surface treatment of molds for oxide glass stamping (2013)

[3] T. Aizawa, Y. Sugita, Prof. 6th SEATUC Conference (2012, Bangkok)

[4] T. Aizawa, T. Fukuda, K. Itoh, International Steel Research (2012)

[5] T. Aizawa, Y. Sugita, Res. Rep. SIT 57-1, (2013) 1-10

[6] T. Aizawa, T. Katoh, S. Muraishi, ISCMCTF-2015, Abstract (2015) (in press)

[7] T. Aizawa, K. Itoh, T. Inohara, Proc. 6th ICOMM. 2010; 77-82

[8] N. Granito, H. Kuwahara, T. Aizawa, J. Materials Science. 37 (2002) 835-844 